\title{
THE MEANING OF A MARKET AND THE MEANING OF “MEANING”
}

\author{
Julian Jonker
}

A

RE THERE ANY viable semiotic objections to commodification? A semiotic objection holds that even if there is no independent consequentialist or deontic objection to marketing a good-such as that it is exploitative or causes third-party harm - there remains a problem with what is said by participating in that market. Consider Michael Sandel's arguments against markets in (among other things) death bets and children. ${ }^{1}$ Sandel claims that, even if these markets are not exploitative, do not exacerbate inequality, and do not set the wrong incentives, they are nonetheless objectionable because of what they express. Betting on a stranger's death in the context of a terrorism-prediction market is wrong because it signals a "dehumanizing attitude." ${ }^{2}$ And even if auctioning off orphans did not result in any harm to them or others, such a "market in children would express ... the wrong way of valuing them."3

Recent discussions have suffered from a basic ambiguity in such talk. The anti-commodificationist who presents a semiotic objection must bear in mind an elementary distinction between two uses of "meaning." As Grice pointed out, there is a difference between saying that smoke on the horizon means fire, and saying that it means there will be war tomorrow. ${ }^{4}$ We could say that in the former case smoke indicates fire because of its causal connection with fire, while in the latter case smoke expresses a call to war because that is the nonnatural meaning given to it by convention or by its place in a communicative practice. Note that causal indication relations are non-revisable, being a matter of natural law, whereas expressive relations are typically revisable because they are grounded in contingent social practices. ${ }^{5}$

It is this distinction that makes a recent anti-anti-commodificationist move

1 Sandel, What Money Can't Buy.

2 Sandel, What Money Can't Buy, 146.

3 Sandel, What Money Can't Buy, 10.

4 Grice, "Meaning."

5 Compare my use of "indication" with that of Crummett, "Expression and Indication in Eth- 
by Jason Brennan and Peter Jaworski particularly compelling. ${ }^{6}$ They argue that if there is no non-semiotic objection to a market in some good, but the market nonetheless has an objectionable meaning, then we should change the meaning of the market to reflect its otherwise unobjectionable nature. For example, if we think the market for surrogate mothers says something degrading about motherhood, though it in no other way does wrong or causes harm, then we should do what we can to change our understanding that the market for surrogate mothers is degrading. Call this the "collapsing move": it collapses a purportedly intrinsic semiotic objection into a consequentialist objection grounded in the contingent costs and benefits of revising the meaning of a market. ${ }^{7}$

The collapsing move gives rise to a dilemma for the semiotic anti-commodificationist. If she thinks that the market has some objectionable non-revisable meaning, then that must be because the existence of the market indicates something objectionable. But then the anti-commodificationist's objection is really a non-semiotic one, since the problem lies with what is indicated. On the other hand, if the anti-commodificationist thinks that the market expresses something objectionable, rather than merely indicating it, then she raises a semiotic objection. But since expressive meaning is revisable, the objection is vulnerable to the collapsing move.

\section{SOME RECENT DEFENSES OF SEMIOTIC OBJECTIONS}

Some recent defenses of semiotic objections fall prey to the Gricean dilemma. Consider Anthony Booth's claim that a market has at least one non-revisable meaning: if a marketed good is incommensurable, then the marketing of that good signals that the good is proto-on-a-par-i.e., (i) a rational choice can be made with respect to choosing between the good and another (it is comparable) and (ii) either the comparison (the rational choice as to how to choose between the goods) has been made or a mechanism is in place for making it. ${ }^{8}$ We put incommensurable goods up for comparison in this way when we adopt norms for choosing between the goods. An individual may do that by accepting the com-

ics and Political Philosophy." Crummett uses "indication" to refer to costly signaling, which I discuss below.

6 Brennan and Jaworski, "Markets without Symbolic Limits."

7 Booth, "The Real Symbolic Limit of Markets," 200.

8 Booth, "The Real Symbolic Limit of Markets," 205n4. The proposal is influenced by Ruth Chang's idea that when we are presented with a hard choice between alternatives this need not be because the alternatives are incomparable, but because they are on a par. See, for example, Chang, "Hard Choices." 
parison offered by the market's price mechanism. In such a case, Booth thinks, the individual's acceptance of the market price noncontingently communicates that they have accepted that the good is up for comparison in this way.

Now it could not be a semiotic objection that the individual has accepted the comparison of what should not be compared. (There may well be prudential or deontic objections.) So Booth objects to the divergence between what the individual's acceptance of a market transaction says and her own beliefs about the good's noncomparability, and this objection is semiotic since it is grounded partly in what the individual's participation in the market says. Such a concern could also be raised at the political level. If a political community accepts the market's incursion into a domain such as sex, then this signals acceptance of the market as the mechanism for comparing sex and money, though the community may fail to collectively believe that sex and money are comparable. If that fails to be straightforwardly hypocritical or dishonest, it is at least inauthentic. As Booth puts it, "the moral wrong of signaling the commodification of sex is that it reflects something about who we are, and it is something we have chosen not to be."

But Booth's claim that commodification "reflects" something about ourselves is subject to the same ambiguity we find in words like "says" and "signals." If what he means is that the fact of participating in a market for sex indicates that the participant has accepted that sex is up for comparison by the market, then whatever objection there is to that is not a semiotic objection. There is in fact little room for an objectionable divergence between what attitude the transaction indicates and what the participant believes about the good's value. What the transaction indicates, at most, is that the participant understands that the market provides a way of comparing the good with money and accepts the terms of their transaction; but that is compatible with believing anything about the value of the good, including that the good is incomparable but that one's best option is to transact on the particular terms of comparison presented by the transaction.

So Booth must have in mind that participation in the market expresses something thicker than mere acquiescence in the terms of the transaction. A prima facie compelling complaint would be that a participant expresses endorsement of the market as a mechanism for comparison, when in fact their own attitude is one of mere acceptance of the market's role. But since endorsement is not indicated by participation in the market, it is open to us to revise that participation in the market expresses endorsement. That is just another instance of the collapsing move.

A similar ambivalence lurks in Mark Wells's objection that charging for an

9 Booth, “The Real Symbolic Limit of Markets," $205 n 4$. 
action that one is obliged to perform (such as rescuing a drowning child, or perhaps voting in a particular way) "necessarily communicate[s], signal[s], express[es], or symbolize[s] the wrong motive."10 This disjunction of verbs is ambiguous between what I have been calling "expression" and "indication." If Wells has identified a problem, it is not with what a seller expresses or indicates, but with the fact that she acts impermissibly. ${ }^{11}$

What of Dustin Crummett's suggestion that costly signaling can give rise to "communicative normative considerations"? ${ }^{12}$ An agent's action sends a costly signal that she has an attitude if she would not perform the action, given its cost, were it not that the action were evidence for her attitude. But costly signaling is primarily a causal indication that the agent wishes the audience to believe she has the attitude (deception is nearby), and whatever objection there is to that is non-semiotic. It is true that costly signaling, when deployed by cognitive sophisticates (e.g., humans rather than peacocks), is capable of blurring the Gricean distinction. ${ }^{13}$ But that is because costly signals are salient points for coordinating upon conventional meanings - so, for example, the costly signaling of gift giving is likely the basis of the conventional meaning of a birthday gift, which may in fact be too inexpensive to count as a costly signal. ${ }^{14}$ So even a sophisticated practice grounded in costly signaling is subject to the Gricean dilemma: what it indicates is not grounds for a semiotic objection, and what it expresses is subject to the collapsing argument.

The most resilient contribution thus far has been Jacob Sparks's anti-com-

Wells, "Markets with Some Limits," 614.

I agree with an anonymous reviewer that Wells is best understood as raising a non-semiotic objection against Brennan and Jaworski's claim that if there is nothing wrong with giving a thing away then there is nothing wrong with selling it. Yet Wells expressly frames his objection as "captur[ing] the concern behind some 'semiotic objections," and describes it as "express[ing] a kind of semiotic objection to markets" (Wells, "Markets with Some Limits," $611,614)$. I am denying this characterization, rather than the viability of the objection.

Crummett, "Expression and Indication in Ethics and Political Philosophy," n6. Crummett is concerned mostly with arguing for egalitarianism, and only hints at an anti-commodificationist argument. The latter argument, made against terrorism-prediction markets, seems to be that it is a psychological fact about people that they find betting on someone's death disrespectful (19). But insofar as an objection is to be grounded in a hardwired attitude toward some activity, it need not identify the attitude as a form of costly signaling, or any other sort of signaling.

13 This leads one evolutionary game theorist to puff that "all meaning is natural meaning"though he immediately agrees that "Grice is pointing to a real distinction." Skyrms, Signals, 1.

The line is also blurred because a signal may be costly in virtue of its conventional meaning. A racist who unrepentantly uses a slur incurs the cost of social stigma; that he is willing to do so is evidence of his racist conviction. 
modificationist claim that "when we allow the buying and selling of certain goods, we are expressing inappropriate attitudes ... toward the closely related goods that can't be bought or sold."15 This claim must be distinguished from Sparks's endorsement of the claim that certain sorts of goods cannot be bought and sold on pain of no longer being the same sort of good. ${ }^{16}$ As Sandel puts it, "the money that buys ... friendship dissolves it, or turns it into something else."17 The same is true of other things, such as acknowledgments and praise and commendations, that are partly constituted by judgment-sensitive attitudes. Sandel's concern is not a semiotic objection, but rather the non-semiotic objection that a market crowds out or destroys the good it purports to trade in.

Instead, the central plank of Sparks's own anti-commodificationism is the claim that "market exchanges always express preferences."18 But is this a semiotic claim? It depends what Sparks means by "preferences." For the economist inclined toward behaviorism, "preferences" means "revealed preferences." ${ }^{19}$ If revealed preferences were simply a description of choice behavior, then the relation between choice and preference would not be an expressive relation but the identity relation. But revealed preferences are subject to assumptions concerning completeness and consistency, which actual choice behavior might violate. ${ }^{20}$ Perhaps then the economist should treat choice behavior as evidence of a psychological attitude that best explains and predicts choice. ${ }^{21}$ If so, the relation between choice and revealed preference is the non-revisable one of indication. That exchange indicates that such an attitude may ground an objection to commodification if the attitude is regrettable and could be discouraged by limiting the market, but the objection is not a semiotic one.

A more interesting interpretation of revealed preference theory is that its assumptions and axioms provide a normative theory of what a rational agent should choose given what she does choose. ${ }^{22}$ Then the theory is misleadingly named, since choice behavior reveals nothing further about the chooser, but in-

15 Sparks, "Can't Buy Me Love," 349. See also Dick, "Transformable Goods and the Limits of What Money Can Buy"; and Stein, "Exchanging for Reasons, Right and Wrong," 10.

Sparks, "Can't Buy Me Love," 341n11, 343-44.

Sandel, What Money Can't Buy, 94n1.

Sparks, “Can’t Buy Me Love,” 341n11.

Samuelson, "A Note on the Pure Theory of Consumer's Behaviour"; Little, "A Reformulation of the Theory of Consumer's Behaviour," esp. 92.

Classic presentations of the theory are Arrow, "Rational Choice Functions and Ordering"; and Sen, "Choice Functions and Revealed Preference." As suggested by Hausman (Preference, Value, and Choice, 23-48), who emphasizes that this psychological attitude only explains choice in conjunction with belief. 
stead commits her to further choices, on pain of being irrational. This relation between choice and preference is not one of identity or indication, but is much more like that between an utterance and the meaning to which the speaker commits herself by uttering it. ${ }^{23}$ Such a rationalist view is not straightforwardly subject to collapse, given that the assumptions of revealed preference theory have the air of rationality about them, and may be difficult or impossible to revise. So a market participant rationally commits herself to the pattern of behavior that rationally follows from her market behavior, and it is this pattern of rational commitment that is communicated by her choices, whether she holds any such commitments or not.

This rationalist claim, not explicitly voiced by Sparks, does present us with grounds for an interesting semiotic objection. But its prospects look dim. Unlike in the case of linguistic phenomena, we are not obviously compelled by nature or practice to construe choice behavior as meaningful in the way that normative revealed preference theory does. We need not apply any norms of consistency and completeness in order to make sense of a person's choice to participate in or endorse a particular market. Unlike a linguistic utterance, a particular choice can be understood without having to be understood against a backdrop of logically related utterances. And in any case, we need not treat as significant the fact that this choice commits the chooser, on pain of inconsistency or incompleteness, to a backdrop of logically related choices. We can focus on other things instead: that the choice is evidence for the chooser's actual attitudes, say, or for the choices that they will and would actually make. The question is whether we should care more about what a person actually thinks and does than what their rational version would do. All ordinary considerations of character and consequence point to the former. But in any case, once we have raised the question of which of these things matters more, we have applied the collapsing move to the normative theory of revealed preference too.

\section{SO WHAT?}

A spectator to this debate may wonder why it matters that an objection is semiotic rather than not. One reason is that a semiotic objection shows that commodification wrongs not just participants and third parties who directly bear negative consequences, but everyone. It is an undeniable part of human nature that we care what others think about us, and also about whether they value the same

a revealed preference is hopelessly torn between descriptive and normative aspirations. On the prospects of a normative theory, see Bermúdez, Decision Theory and Rationality, 43-76.

For this influential view of meaning, see Davidson, "Truth and Meaning." 
things that we value. For example, we blame some hypocritical acts that do not directly affect us because the hypocrite thereby shows contempt for our equal moral standing. ${ }^{24}$ And we blame the person who aims a slur at another not just because the addressee feels hurt, but because of the offense caused even to those not addressed, or because it undermines their equal standing. ${ }^{25}$ Another reason for caring about a distinctively semiotic objection is that it names an intrinsic defect in a market, and so is not hostage to empirically testable claims about whether the market causes harm.

But an objection to commodification need not be semiotic in order to have these features. If a market for intimate services corrupts our ability to have genuine intimate relations, then it (non-expressively) harms all of us who could benefit from intimate relations. And if contingent gender disparities are such that a market for intimate services is inevitably unfair, then it is an intrinsic defect that the market is inevitably unfair in such circumstances. If commercial surrogacy involves the adoption of disrespectful attitudes toward motherhood, then it may (non-expressively) wrong all mothers if such a disrespectful attitude also counts as disrespecting mothers. And if one who engages in commercial surrogacy necessarily has such attitude, then there is an in-principle objection to such a market.

My argument has been skeptical about the possibility of semiotic objections, and their necessity, but it should not be understood as an anti-anti-commodificationist argument. All I hope to have shown is that the concerns raised by anti-commodificationists are not plausibly semiotic objections. Yet they remain plausible objections. Perhaps it is better to call some of them "symptom-identifying" or "etiological objections," since they complain that markets appear somewhere in a causal chain involving objectionable behavior. When Anderson complains that commercial surrogacy undermines the intimacy involved in parenting relationships, her complaint is not that participating in a market expresses something objectionable about parenting, but that it indicates that parenting relationships are being impaired or are vulnerable to impairment. ${ }^{26}$ Or consider a concern Satz raises about prostitution when she says that it "represents women as sexual servants to men."27 Suppose that it does. Whatever bite this complaint has lies in the fact that, at least in some cases, perhaps the paradigmatic ones, prostitution in fact involves women acting as sexual servants to men. That a practice represents women as servants is surely of secondary importance to the fact that it sufficiently often does make women into servants. The problem is not, as

Wallace, "Hypocrisy, Moral Address, and the Equal Standing of Persons."

5 Feinberg, Offense to Others; Waldron, The Harm in Hate Speech.

26 Anderson, "Is Women's Labor a Commodity?"

Satz, Why Some Things Should Not Be for Sale, 144. 
Satz puts it, that prostitution is a "theatre of inequality," but that it is a site of actual inequality. ${ }^{28}$ In sum, while a purportedly semiotic objection sometimes deflates into a weak consequentialist objection, it sometimes inflates into a strong non-consequentialist objection. ${ }^{29}$

Indeed, I think it is not in the anti-commodificationist's interest to emphasize an objection's expressive dimension. First, doing so renders the anti-commodificationist open to the taunt that they are a snowflake. The move here is similar to the collapsing move: one who feels demeaned or insulted by what commodification says could just as well change how they feel about what is said. Or perhaps the anti-anti-commodificationist will say, plausibly if not persuasively, that we should not take hurt feelings as seriously as freedom and welfare improvements. Second, it allows the anti-anti-commodificationist to defend essentially economic activity on the basis of considerations of expressive freedom. Such arguments, seemingly on the rise in American law, are a distortion. ${ }^{30}$ Not all forms of distinctively human interaction must be understood as communication. Economic exchange is a form of interaction that implicates our attitudes about the values of things. But we neither can nor need say what we think about the values of things by agreeing to exchange one quantity of one thing for another quantity of another thing. Economic exchange is primordial but inarticulate, a poor neighbor of our rich representational capacities when it comes to express-

An etiological objection is not an impure semiotic objection, which David Dick describes as a complaint that a market exchange "sends a message that results in some [non-semiotic] wrong” ("Impure Semiotic Objections to Markets," 231, italics omitted). An impure objection presupposes that market exchange "sends a message" in the expressive sense, and is therefore open to the collapsing move. In contrast, an etiological objection is a complaint against whatever is indicated by participation in or endorsement of market exchange, and has nothing to do with what is expressed by that exchange. Similarly, an etiological objection should not be thought of as a complaint against the fact that "a bad message is expressed because some other independent wrong occurs" ("Impure Semiotic Objections to Markets," 231, italics omitted). An etiological objection is not a complaint against a message, but against a state of affairs. See also Brennan and Jaworski, "Markets without Symbolic Limits," 1056 n6.

Consider recent decisions by the U.S. Supreme Court to the effect that companies have a First Amendment right to unlimited financing of political broadcasts (Citizens United v. Federal Election Commission, 558 U.S. 310 [2010]), or that agency fees charged by public sector unions violate the First Amendment rights of nonmembers (Janus v. American Federation of State, County, and Municipal Employees, Council 31, 138 S. Ct. 2448 [2018]). See, more generally, Shanor, "The New Lochner." 
ing who we are and what we value. Philosophy, and politics, should not give it more than its due. ${ }^{31}$

Wharton School of the University of Pennsylvania jonker@wharton.upenn.edu

\section{REFERENCES}

Anderson, Elizabeth S. "Is Women's Labor a Commodity?” Philosophy and Public Affairs 19, no. 1 (Winter 1990): 71-92.

Arrow, Kenneth J. "Rational Choice Functions and Ordering." Economica 26, no. 102 (May 1959): 121-27.

Bermúdez, José Luis. Decision Theory and Rationality. Oxford: Oxford University Press, 2009.

Booth, Anthony R. "The Real Symbolic Limit of Markets." Analysis 78, no. 2 (April 2018): 198-207.

Brennan, Jason, and Peter Jaworski. "Markets without Symbolic Limits." Ethics 125, no. 4 (July 2015): 1053-77.

Chang, Ruth. "Hard Choices." Journal of the American Philosophical Association 3 , no. 1 (Spring 2017): 1-21.

Crummett, Dustin. "Expression and Indication in Ethics and Political Philosophy." Res Publica (forthcoming).

Davidson, Donald. "Truth and Meaning." In Inquiries into Truth and Interpretation, 17-36. Oxford: Oxford University Press, 1984.

Dick, David. “Impure Semiotic Objections to Markets." Public Affairs Quarterly 32, no. 3 (July 2018): 227-46.

_ . "Transformable Goods and the Limits of What Money Can Buy." Moral Philosophy and Politics 4, no. 1 (May 2017): 121-40.

Feinberg, Joel. Offense to Others. Oxford: Oxford University Press, 1985.

Grice, H.P. “Meaning." Philosophical Review 66, no. 3 (July 1957): 377-88.

Hausman, Daniel M. Preference, Value, and Choice. Cambridge: Cambridge University Press, 2012.

Little, I.M.D. "A Reformulation of the Theory of Consumer's Behaviour." Oxford Economic Papers 1, no. 1 (January 1949): 90-99.

31 I am grateful to Anthony Booth, Matt Caulfield, Ruth Chang, Amanda Shanor, Alan Strudler, two anonymous reviewers, and participants in the Wharton School Legal Studies and Business Ethics Half Full Workshop for encouragement and insightful comments. 
Samuelson, Paul. "A Note on the Pure Theory of Consumer's Behaviour." Economica 5, no. 17 (February 1938) 61-71.

Sandel, Michael. What Money Can't Buy. New York: Farrar, Straus and Giroux, 2012.

Satz, Debra. Why Some Things Should Not Be for Sale: The Moral Limits of Markets. New York: Oxford University Press, 2010.

Sen, Amartya K. "Behaviour and the Concept of Preference." Economica 40, no. 159 (August 1973): 241-59

- "Choice Functions and Revealed Preference." Review of Economic Studies 38 , no. 3 (July 1971): 307-17.

Shanor, Amanda. “The New Lochner." Wisconsin Law Review 2016, no. 1 (2016): 133-206.

Skyrms, Brian. Signals: Evolution, Learning, and Information. Oxford: Oxford University Press, 2010.

Sparks, Jacob. “Can't Buy Me Love: A Reply to Brennan and Jaworski." Journal of Philosophical Research 42 (2017): 341-52.

Stein, Joshua. "Exchanging for Reasons, Right and Wrong." Journal of Value Inquiry (forthcoming).

Waldron, Jeremy. The Harm in Hate Speech. Cambridge, MA: Harvard University Press, 2012.

Wallace, R. Jay. "Hypocrisy, Moral Address, and the Equal Standing of Persons." Philosophy and Public Affairs 38, no. 4 (Fall 2010): 307-41.

Wells, Mark. "Markets with Some Limits." Journal of Value Inquiry 51, no. 4 (December 2017): 611-18. 